\title{
Seeking truer measures of success: Moving toward more rigorous evaluations of industry-led access to medicines programs
}

\author{
Cherie Lynn Ramirez ${ }^{1,2,3}$, Ashveena Gajeelee ${ }^{1,3}$, Brianna Desharnais ${ }^{2}$, \\ Jenna Sherman ${ }^{1,4}$, Dexter Waters ${ }^{1,5}$
}

${ }^{1}$ Global Access in Action, Harvard University Berkman Klein Center for Internet \& Society, Cambridge, Massachusetts, USA ${ }^{2}$ Simmons University, Boston, Massachusetts, USA

${ }^{3}$ Ariadne Labs, Brigham and Women's Hospital and Harvard T.H. Chan School of Public Health, Boston, Massachusetts, USA ${ }^{4}$ Harvard T.H. Chan School of Public Health, Boston, Massachusetts, USA

${ }^{5}$ Thomas Jefferson University, Philadelphia, Pennsylvania, USA

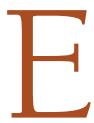
quitable access to essential medicines and diagnostic tools is crucial for improving global public health and promoting sustainable health development efforts. Many individuals suffering from health challenges around the world still do not have access to existing life-saving interventions due to lack of availability and high costs. The devastating effects of these inequities and discussions about their solutions have been at the forefront during the COVID-19 pandemic.

We offer a timely summary of the latest efforts to improve the evaluation of industry-led access to medicines (AtM) programs, highlighting the recently released 2021 Access to Medicines Index Report and the Second World Health Organization (WHO) Model List of Essential In Vitro Diagnostics.
Health experts have long been working to identify effective methods of increasing access to medicines (AtM) that also incentivize research and development (R\&D) by drug manufacturers. In the last two decades, the number of industry-led AtM programs implemented has substantially increased [1], with the pharmaceutical industry more openly recognizing a human rights obligation to improve access to medicines [2]. As argued by the Lancet Commission on Essential Medicines Policies, despite the existence of many industry-led AtM programs and the independent AtM Index that ranks 20 of the world's largest R\&D-based pharmaceutical companies, rigorous evaluation remains a key challenge [3]

In response, the 2021 AtM Index report adapted various indicators to expand how it measures companies' evaluation efforts and used tighter analytical framework centered on governance of access, research and development, and product delivery [4]. Figure 1 illustrates a representative set of indicators that were changed between the 2018 and 2021 reports, with a full listing provided in Figure S1 in the Online Supplementary Document. This most recent report was released in January 2021 to assess the actions taken by pharmaceutical companies to expand access to medicine for people living in low- and middle-income countries. It also captures the industry's response to the ongoing pandemic, identifying 63 new R\&D projects in companies' pipelines targeting COVID-19. The report also highlighted that the COVID-19 pandemic has caused 


\begin{tabular}{|l|l|}
\hline \multicolumn{1}{|c|}{ 2018 Indicators } & \multicolumn{1}{|c|}{ 2021 Indicators } \\
\hline \multicolumn{1}{|c|}{ Previous Indicator } & \multicolumn{1}{|c|}{ Current Indicator } \\
\hline $\begin{array}{l}\text { A.I.1 Management Structures } \\
\text { Required a board member for AtM program. } \\
\text { A.III.3 Performance Management and Incentives } \\
\text { Created an internal reward systems for employer } \\
\text { performance. }\end{array}$ & $\begin{array}{l}\text { GA1 Governance Structures and Incentives } \\
\text { Created an assessment to determine if in-country } \\
\text { managers are incentivised in AtM initiatives. } \\
\text { AtM objectives are given priority. }\end{array}$ \\
\hline $\begin{array}{l}\text { B.II.3 Disclosure of Market Strategy and Practice } \\
\text { Provided public information on marketing. } \\
\text { B.I.1 Governance of Ethical Marketing } \\
\text { Enforced ethical marketing code. }\end{array}$ & $\begin{array}{l}\text { GA4 Responsible Promotional Practices } \\
\text { Emphasized responsible sales practices and public } \\
\text { disclosure of interactions between companies and medical } \\
\text { professionals. }\end{array}$ \\
\hline $\begin{array}{l}\text { C.II.1 Disclosure of Resources Dedicated to R\&D } \\
\text { Required public information on research and } \\
\text { development in the Index Disease category. }\end{array}$ & $\begin{array}{l}\text { RD4 Disclosure of Resources Dedicated to R\&D } \\
\text { Enforced publicity of research and development endeavors } \\
\text { to the public for financial investment. }\end{array}$ \\
\hline $\begin{array}{l}\text { C.I.4 Clinical Trial Conduct: Post-Trial Access } \\
\text { Rated AtM after trial periods. }\end{array}$ & $\begin{array}{l}\text { RD5 Clinical Trial Conduct: Post-Trial Access } \\
\text { Emphasized affordability and availability of products } \\
\text { post-trial. }\end{array}$ \\
\hline $\begin{array}{l}\text { F.II.2 Capacity Building in R\&D } \\
\text { Created standard timeframes for reporting cases of of } \\
\text { substandard and falsified (SF) medicines. }\end{array}$ & $\begin{array}{l}\text { PQ2 Reporting Falsifited and Substandard Medicines } \\
\text { Specified SF medicines and timeline. }\end{array}$ \\
\hline & $\begin{array}{l}\text { PP2B Access Strategies: Long Term Donation } \\
\text { Programs } \\
\text { Rated long-term, sustainable product donation programs } \\
\text { with public disclosure of goals. }\end{array}$ \\
\hline & $\begin{array}{l}\text { PP3 Access Strategies: Health Care } \\
\text { Practitioner-administered Products } \\
\text { Consideration both the ability-to-pay of the } \\
\text { reimbursement authority and the demographics } \\
\text { characteristics of a country across the income pyramid. }\end{array}$ \\
\hline
\end{tabular}

Figure 1. A small representative set of indicators are presented that were changed between the 2018 and 2021 Access to Medicines Index reports. A comprehensive listing of indicators and the changes between those used in 2018 and 2021 are provided in Figure S1 in the Online Supplementary Document. further problems with funding competition for other AtM initiatives, such as to combat malaria, TB, and HIV/AIDS [5]. The Index reported that all 20 companies assessed now take steps to measure outcomes of AtM initiatives, up from 13 companies in 2018. Outcomes are made public for more than half of initiatives assessed (43 of 82). Also released in January 2021 was the Second World Health Organization (WHO) Model List of Essential In Vitro Diagnostics (EDL), which provides a comprehensive list of diagnostic tests necessary for universal health coverage that can be tailored to local circumstances [6]. The latest edition was revised to include COVID-19 nucleic acid amplification and antigen detecting tests as a necessary In Vitro Diagnostics. The WHO has previously worked with many countries to make noncommunicable disease diagnostic testing available in low- and middle-income countries, which has led to the development of resources like the National Free Diagnostic Service Initia-

tive, which provides services in India [7]. Similar resources for COVID-19 are essential to stopping the spread of COVID-19 and improving global health.

In addition to the AtM Index, another major effort to improve reporting on AtM programs is Access Accelerated and its Access Observatory, which attempts not only to collect data, which is made publicly available, but also to devise a standardized measurement framework [8]. Their evaluation of pilot programs in the Philippines and Ghana suggests that differential pricing aided with health care strengthening can increase access to medicines [9].

A variety of factors continue to serve as barriers to conducting widespread, robust program evaluations, including the lack of specific data about drugs, quality medicine pricing data, and household usage of drugs. In addition, companies often lack incentives to collect and report high-quality impact data.

\section{The need to promote greater rigor and transparency in AtM programs is essential to understanding how well these programs are actually doing to achieve desired goals to increase ac- cess and improve health outcomes.}

Despite these challenges, there are a small number of pharmaceutical companies that have conducted robust evaluations in the past. While none of the 120 AtM initiatives evaluated by Rockers et al. in 2017 met the highquality threshold under the Grading of Recommendations, Assessment, Development and Evaluation (GRADE) system, three studies were classified as moderate quality: (1) Merck MSD's Mectizan Donation Program, (2) the Pfizer International Trachoma Initiative, and (3) Novartis's Access program in Kenya. The Novartis Access study was the first randomized assessment of the impact of a pharmaceutical industry-led AtM program, and initial results indicate that even offering medicines at US\$1 per treatment per month did not significantly improve overall access nor reduce prices of the medicine after one year [10]. The study will be extended over a two-year period to test the factors which might have contributed to these results, which underscores the need for rigorous evaluations to understand and overcome barriers to access.

Program design varies widely between AtM initiatives, with the 120 AtM initiatives assessed in 2017 employing the following strategies: medicine donation (48\%), price reduction (44\%), licensing agreements (22\%), and supply chain strengthening (11\%). It has been found that bulk donations are more likely to be unsustainable and even cause harm in the long run by reducing competition [11]. General price reduction as a strategy alone may run the risk of not addressing other accessibility issues in a specific region. Increasing the quality of 


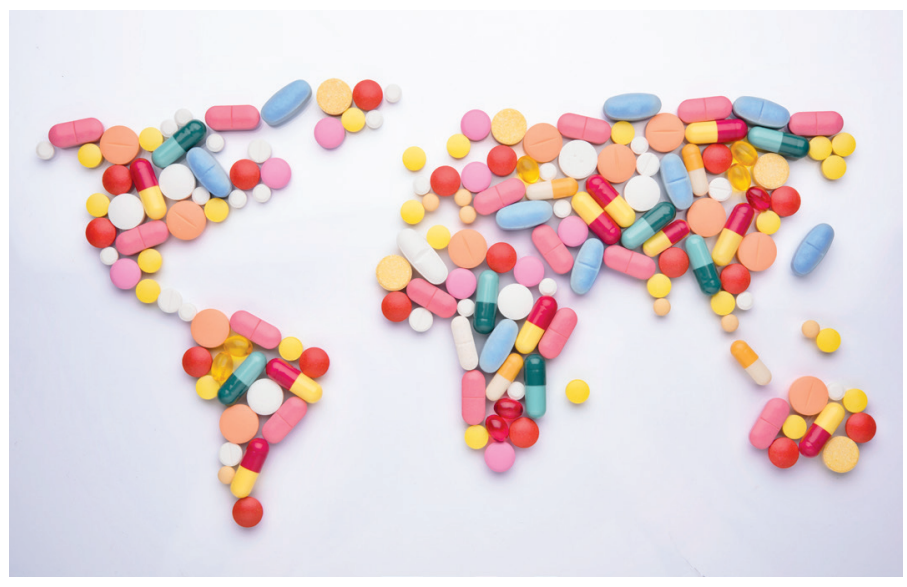

Photo: Image credit: @pogonici/123RF.COM.

evaluations is necessary to determine the success of certain AtM strategies in a variety of contexts. More innovative, long-term approaches to improving AtM should also be explored, including differential pricing, voluntary licensing, and patent pooling [12]. Some of the metrics revised for the 2021 AtM Index aim to better measure the scale and long-term sustainability of companies' AtM strategies.

The urgent need to overcome COVID-19 has prioritized AtM among global leaders. In May 2020, the World Health Assembly adopted a resolution that calls for increased collaboration through "existing mechanisms for voluntary pooling and licensing of patents" to mitigate the COVID-19 pandemic and for "equitable access to and fair distribution of all essential health technologies and products to combat the novel coronavirus." The resolution was co-sponsored by more than 130 countries and adopted by consensus [13]. Coupling expanded access with more rigorous and transparent evaluations will help ensure that best practices lead to desired outcomes and minimize unintended consequences. Fortunately, many actors across industry, academia, and public health recognize the need to prioritize equity, accountability, independence, and sound evidence. In doing so, companies can move toward strengthening their reputations while increasing meaningful impact that has the potential to save lives.

Funding: BD was supported by the Semester Undergraduate Research Program at Simmons (SURPASs).

Authorship contributions: CLR conceptualized this work. CLR, DW, and JS wrote the first draft. All of the authors researched, revised, and approved the final draft.

Competing interests: The authors completed the ICMJE Unified Competing Interest form (available upon request from the corresponding author) and declare no conflicts of interest.

Additional material

Online Supplementary Document

1 Rockers PC, Wirtz VJ, Umeh CA, Swamy PM, Laing RO. Industry-led access-to-medicines initiatives in low- and middle-income countries: Strategies and evidence. Health Aff (Millwood). 2017;36:706-13. Medline:28373337 doi:10.1377/ hlthaff.2016.1213

2 Hunt P. Report of the Special Rapporteur on the right of everyone to the enjoyment of the highest attainable standard of physical and mental health. United Nations. 2008. Available: https://www.who.int/medicines/areas/human_rights/A63_263.pdf. Accessed: 13 March 2021.

3 Wirtz VJ, Hogerzeil HV, Gray AL, Bigdeli M, de Joncheere CP, Ewen MA, et al. Essential medicines for universal health coverage. Lancet. 2017;389:403-76. Medline:27832874 doi:10.1016/S0140-6736(16)31599-9

4 Pharma's path to 2030 captured in new framework for next Access to Medicine Index. Access to Medicine Foundation. 2020. Available: https://accesstomedicinefoundation.org/news/pharmas-path-to-2030-captured-in-new-framework-for-nextaccess-to-medicine-index. Accessed: 13 March 2021.

5 Access to Medicine Foundation. Access to medicine index 2021. 2021. Available: https://accesstomedicinefoundation.org/ publications/2021-access-to-medicine-index. Accessed: 13 March 2021

6 World Health Organization. Second WHO model list of essential in vitro diagnostics. 2019. Available: https://www.who.int/ medical_devices/publications/Second_WHO_Model_List_of_Essential_In_Vitro_Diagnostics/en/. Accessed: 13 March 2021.

7 Pai M. To improve access to diagnostics, countries must adapt the WHO essential diagnostics list. Forbes. 2021. Available: https://www.forbes.com/sites/madhukarpai/2021/02/01/who-essential-diagnostics-list-expands-to-include-covid-19-andmuch-more/?sh=5ab34bd43323. Accessed: 13 March 2021.

8 Access Observatory. Access observatory. Available: https://www.accessobservatory.org/. Accessed: 13 March 2021.

9 Mobula LM, Sarfo S, Arthur L, Burnham G, Ansong D, Plange-Rhule J, et al. A novel initiative to improve access to medicines for control of non-communicable diseases in low-and middle- income countries [version 2; peer review: 1 approved, 1 approved with reservations, 1 not approved]. Gates Open Res. 2018;2:12. doi:10.12688/gatesopenres.12798.2 
10 Rockers PC, Laing RO, Ashigbie PG, Onyango MA, Mukiira CK, Wirtz VJ. Effect of Novartis Access on availability and price of non-communicable disease medicines in Kenya: a cluster-randomised controlled trial. Lancet Glob Health. 2019;7:e492-502. Medline:30799142 doi:10.1016/S2214-109X(18)30563-1

11 Baker BK, Ombaka E. The danger of in-kind drug donations to the Global Fund. Lancet. 2009;373:1218-21. Medline:18848353 doi:10.1016/S0140-6736(08)61487-7

12 Palfrey Q. Expanding access to medicines and promoting innovation: A practical approach. Georgetown Journal on Poverty Law \& Policy. 2017;24:161-204.

13 World Health Organization. 73rd World Health Assembly Agenda Item 3: COVID-19 response. 2020. Available: https://apps. who.int/gb/ebwha/pdf_files/WHA73/A73_CONF1Rev1-en.pdf. Accessed: 13 March 2021

\section{Correspondence to:}

Cherie Lynn Ramirez, PhD

Department of Chemistry \& Physics

Simmons University

300 The Fenway

Boston, MA 02115

USA

cherielynn@post.harvard.edu 